\title{
Research Paper \\ The Effectiveness of Affective-reconstructive Couple Therapy in Increasing the Trust and Marital Satisfaction of Couples With Remarriage
}

\author{
${ }^{*}$ Gholamreza Rajabi ${ }^{1}$, Ghasem Khoshnoud ${ }^{1} \odot$, Mansour Soudani ${ }^{1}$, Reza Khojastehmehr ${ }^{1}$
}

Key words:

Affective-reconstructive couple therapy, Trust in close relationships, Marital satisfaction, Remarriage

\begin{abstract}
A B STRACT
Objectives This study aimed to determine the effectiveness of affective-reconstructive couple therapy in increasing the trust in close relationships and marital satisfaction of couples with remarriage and divorce experience.

Methods This is a single-case experimental study with a non-concurrent multiple baseline design. Three distressed couples were selected from among couples with remarriage and divorce experience referred to private and government counseling centers in Ahvaz, Iran, based on inclusion/exclusion criteria using purposive sampling method during September-December 2018, They participated at eight sessions of affective-reconstructive couple therapy, once a week each 90 minutes. They completed the Trust in Close Interpersonal Relationships Questionnaire and Marital Satisfaction Scale before and after treatment, and at the follow-up period. The data analysis was conducted by using visual analysis (graph drawing), reliable change index, recovery rate formula (increase rate), and normative comparison methods. Results Affective-reconstructive couple therapy increased the trust in close relationships and marital satisfaction in couples after treatment and at the follow-up period.

Conclusion Affective-reconstructive couple therapy, due to special attention to the couples' past relationships and increasing their insight into the causes of distress development in relationship can increase the trust in close relationships and marital satisfaction in remarried couples with divorce experience.
\end{abstract}

\section{Extended Abstract}

\section{Introduction}

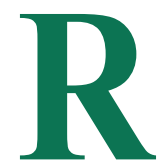

emarriage is a chance for individuals who have lost a spouse to experience married life once more. This is increasingly becoming a normative event in different societies such that in almost half of today's marriages, one or both couples have a previous marriage experience. Couples with remarriage report higher levels of conflicts, incompatibility, and tensions compared to those in a first marriage which is the result of unique dynamism within such families. Working with remarried couples has different difficulties and challenges, compared to working with couples who are in a first marriage. For this reason, the counselor needs to take into account these apparent differences.

\section{Method}

This is a single-case experimental study with a non-concurrent multiple baseline design. Three distressed couples -

* Corresponding Author:

Gholamreza Rajabi, PhD.

Address: Department of Counselling, Faculty of Education and Psychology, Shahid Chamran University of Ahvaz, Ahvaz, Iran.

Tel: +98 (61) 33331366

E-mail: rajabireza@scu.ac.ir 
were selected during September-December 2018 from among couples with remarriage and divorce experience referred to private and government counseling centers in Ahvaz, Iran using purposive sampling method and based on inclusion criteria (age 25-45 years, no any mood disorder, no drug addiction, having at least one year of married life, having at least a high school diploma, ability to speak in Farsi fluently, and willingness to participate in the study), the Structured Clinical Interview for DSM-5 score, and having a Marital Satisfaction Scale score $<22$ [21]. The exclusion criteria were: being first-married, taking psychiatric medications, receiving other therapies concurrently, and tending to get divorced or separated. The couples received affective-reconstructive couple therapy in eight 90-min sessions once a week. The trust in close relationships and marital satisfaction variables were measured in 3,5 , and 8 sessions. In addition, a 45-days follow-up was conducted after the end of treatment. The measurements were carried out using the Trust in Close Interpersonal Relationships Scale (1985), and Marital Satisfaction Scale (2010) at baseline, after intervention, and at follow-up period. Data were analyzed by using visual analysis (graph drawing), Reliable Change Index (RCI), recovery rate formula (increase rate), and normative comparison.

\section{Results}

The findings of this study concerning 'trust in close relationships' variable showed that the mean baseline score was 67.75 for the first couple, 68.33 for the second couple, and 69.25 for the third couple, while the mean posttest scores increased to 87, 87.16, and 89.66 for the first, second, and third couples, respectively. At the follow-up stage, the mean scores were increased by $28 \%, 27 \%$, and $29 \%$ for the first, second, and third couples, respectively. In the follow-up stage, the differences were significant $(>25 \%)$ for the three couples.

The RCI values after intervention and at the follow-up stage were obtained 2.36 and 3.22, 2.31 and 3.45, and 2.50 and 3.34 for the first, second, and third couples, respectively. This change in this index was significant in the three couples $(Z=1.96, P<0.05)$. These findings demonstrate that affective-reconstructive couple therapy has an important effect on the trust within close relationships compared to the baseline scores.

The mean score for marital satisfaction at baseline was obtained 33.25, 3.16, and 34.87 for the first, second, and third couples, respectively. This score increased to 42.83 in the first, 43.33 in the second, and 42.16 in the third couples after intervention. In the follow-up stage, it was 48.5, 48, and 42.5 for the first, second, and third couples, respectively, indicating more increase in comparison with the baseline and post- test scores. The increase in marital satisfaction after intervention and at the follow-up stage were $29 \%$ and $46 \%$ for the first couple, $30 \%$ and $44 \%$ for the second couple, and $24 \%$ and $22 \%$ for the third couple, respectively. The mean posttest RCI values of the first, second, and third couples were 3.23, 3.43 , and 2.46 , respectively. These changes were significant for all couples after intervention and at the follow-up stage $(\mathrm{Z}=1.96, \mathrm{P}<0.05)$, indicating that the significant effect of affective-reconstructive couple therapy, where its effect was higher on the second couple and lower on the third couple.

\section{Discussion}

This study was an attempt to examine the effect of affective-reconstructive couple therapy on trust in close relationships and marital satisfaction of remarried couples with divorce experience. Result from visual analysis and clinical significance demonstrated that affective-reconstructive couple therapy had a significant effect on their trust in close relationships and marital satisfaction. Identifying and normalizing the distinctive factors in remarriage such as the pain due to loss of previous marriage, and the fantasies and expectations that come with it is an important key to successful interventions for couples with remarriages.

Affective-reconstructive couple therapy reflects an insight-oriented approach to couple therapy, where it is assumed that the couples' current problems often stem from their damage from previous relationships. Such damages can lead to a sustained interpersonal vulnerability and related defense strategies that impede emotional intimacy. When one becomes aware of the origin of one's dysfunctional patterns, life and relationships take on a new meaning for her/him. A process that is applied mutually on both couples gradually provides them with efficient tools to be able to put aside their negative interactions and inappropriate personality tratits.

\section{Ethical Considerations}

\section{Compliance with ethical guidelines}

All ethical principles are considered in this article. The participants were informed about the purpose of the research and its implementation stages; they were also assured about the confidentiality of their information.

\section{Funding}

This study was extracted from the $\mathrm{PhD}$. thesis of the second author, Department of Counselling, Faculty of Education and Psychology, Shahid Chamran University. 


\section{Authors contributions}

Conceptualization, investigation: all authors; Methodology, writing - review \& editing: Gholamreza Rajabi; Writing - original draft: Gholamreza Rajabi, Ghasem Khoshnoud; Funding acquisition, resources: Ghasem Khoshnoud; Supervision: Gholamreza Rajabi, Mansour Soudani, Reza Khojastehmehr.

\section{Conflicts of interest}

The authors declared no conflict of interest

\section{Acknowledgements}

The authors would like to thank the Ravan Asa Counseling Center in Ahvaz city for their valuable cooperation. 


\title{
اثربخشى زوجدرمانى مبتنى بر بازسازى عاطفى بر افزايش اعتماد و رضايت زناشويى در زوجين با ازودواج مجدد
}

\author{
"غلامرضا رجبى' •، قاسم خشنود' •، منصور سودانى '، رضا خجستهمهر' \\ ا. كروه مشاوره، دانشكده علوم تربيتى و روانشناسى، دانشكاه شهيد جمران اهواز، اهوازء، ايران.
}

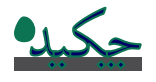

زدافل اين يرؤهش با هدف بررسى اثربخشى زوجدرمانى مبتنى بر بازٔسازى عاطفى بر افزايش اعتماد در روابط نزديك و رضايت زناشويى در

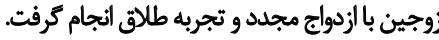

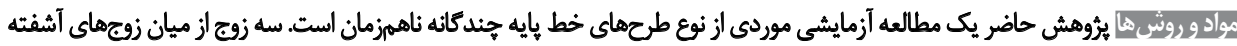

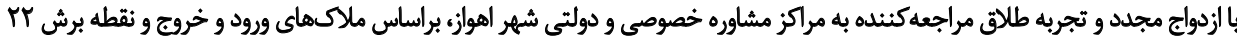

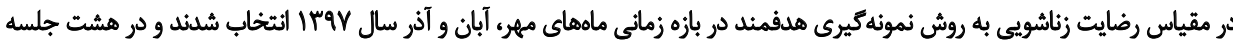

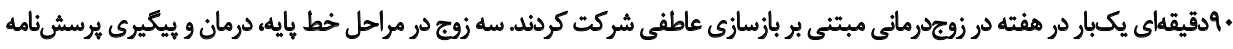

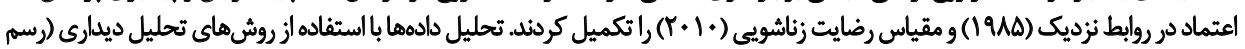

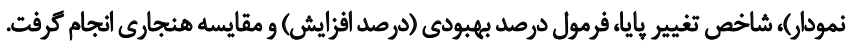

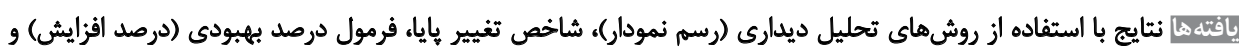

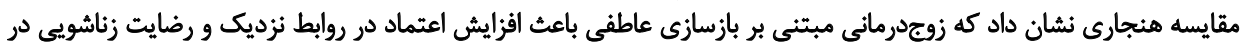

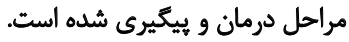

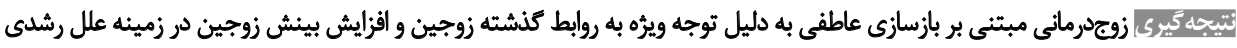

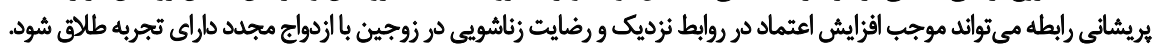

تاريخ دريافت: Tra ارديبهت

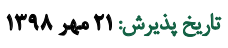
تاريخ انتشار: "ا فروردين

كليدوارڤها:

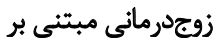
بازسازى عاطفى، اعتماد در روابط نزديك، رضايث إنفيث زناشويي، ازدواج مجدد نزي رضي

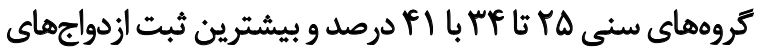

مقدمه

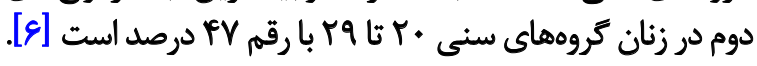

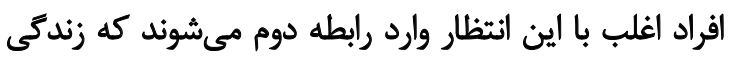

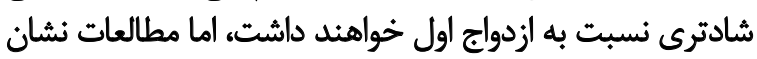

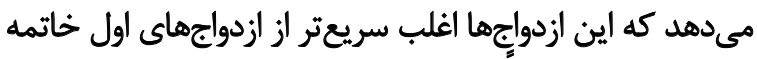

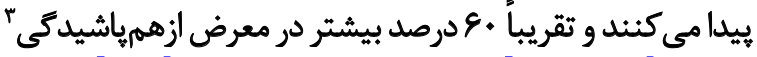

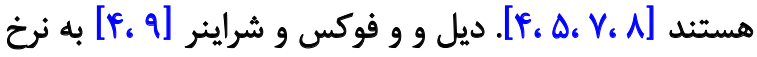

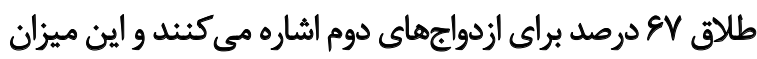

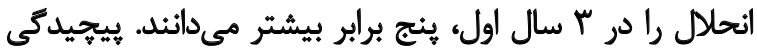

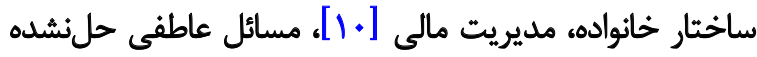

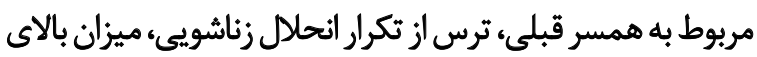

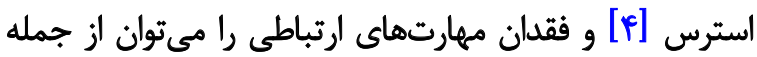
دلايل نايايدارى ازدواج دوم در نظر مرفت إنت

$$
\text { 1. Remarriage }
$$

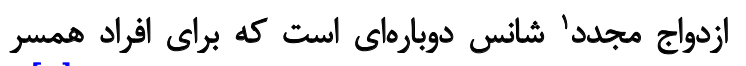

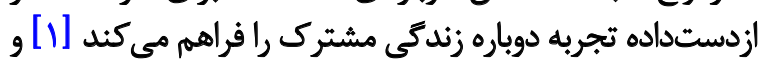

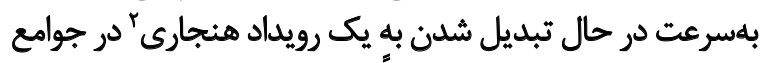

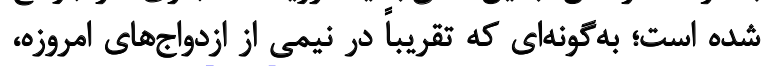

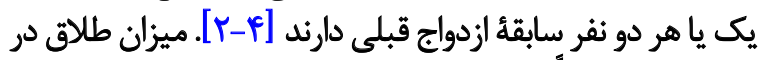

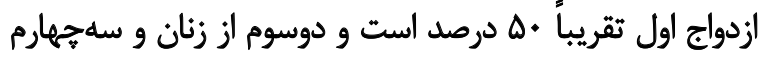

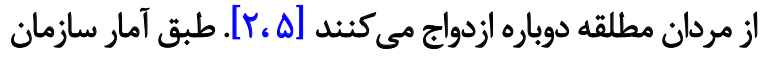

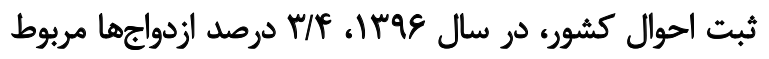

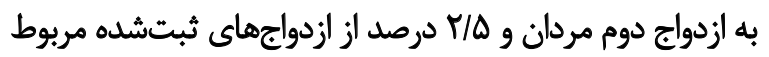

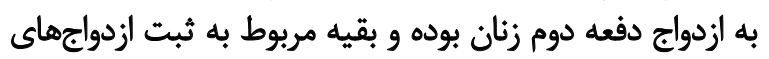

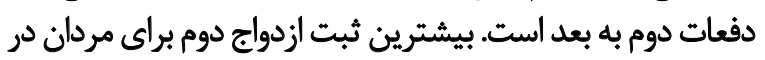 \\ 2. Normative}


كذشته حياتى بودند نشاندهنده راهحل هاى نامناسب و انحرافى

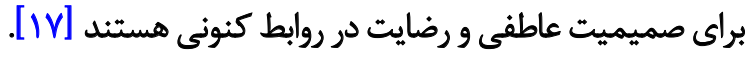

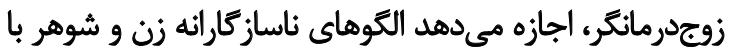

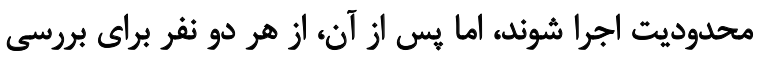

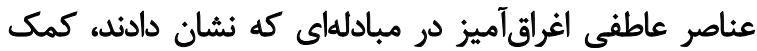

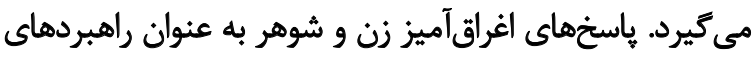

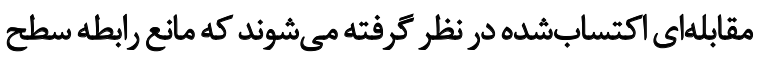

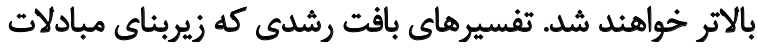

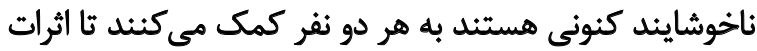

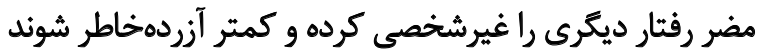
و درنتيجه واكنش متقابل آنها نيز حالت كانت منفى كمتر كترى داشته

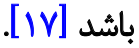

در كل، با توجه به يافتههاى ثروهشى در مورد ازدواج مجدد،

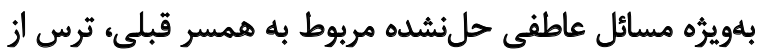

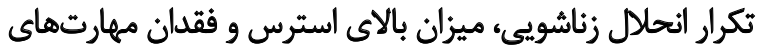

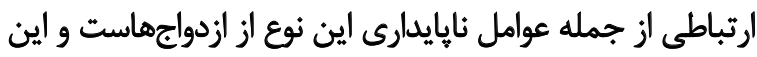

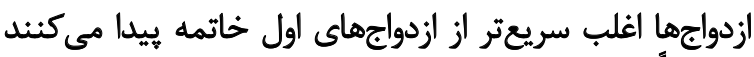

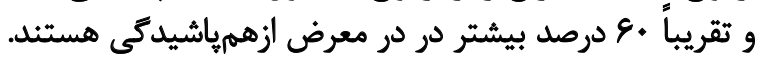

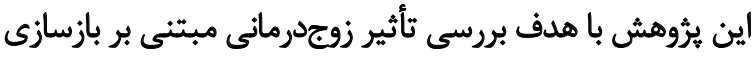

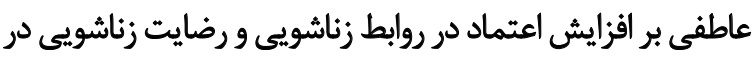
زوجين با ازدواج مجدد انجام كرفت.

\section{وروش}

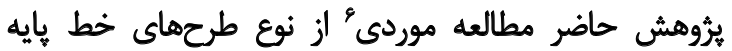

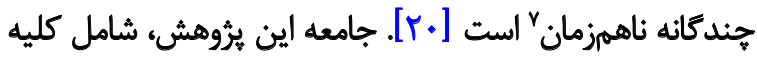

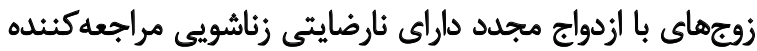

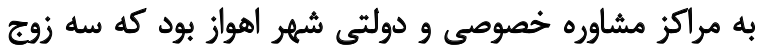

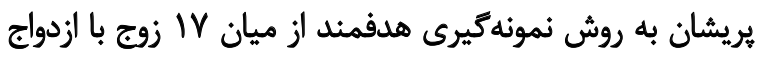

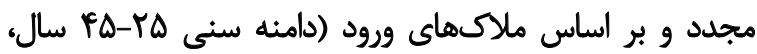

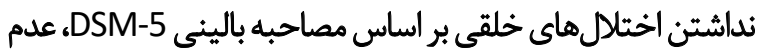

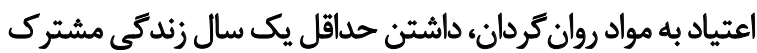

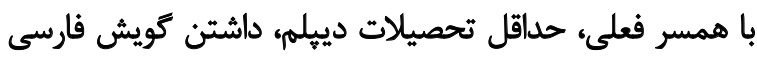

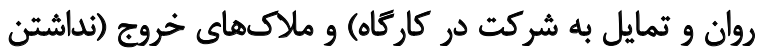

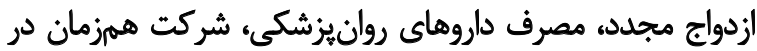

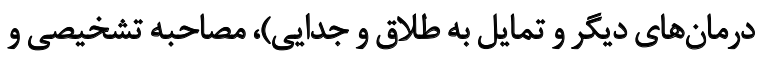

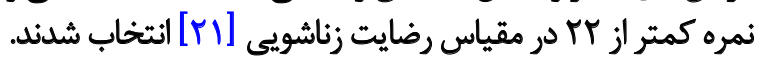

براى انتخاب جامعه هدف از روشهاى مختلف ماندئ ماند فراخوان

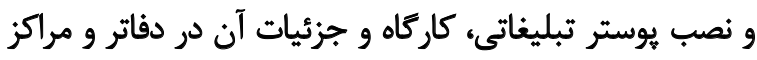

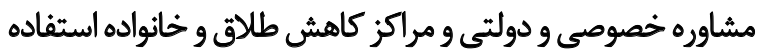
شد و از زوجها براى شركت در اين برنامه درمانى دعوت بون به عمل

6. Single case

7. Non- concurrent multiple baseline designs
در الزدواجهاى اول، زوجين اجازه دارند زمائي را براي بهبيود

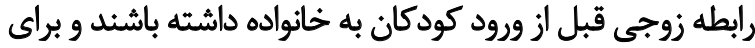

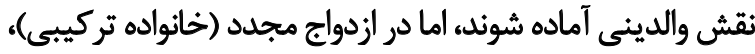

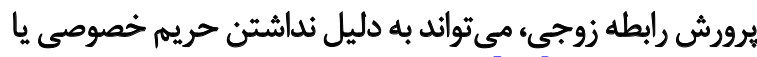

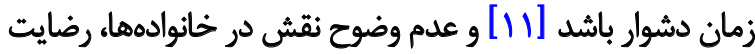

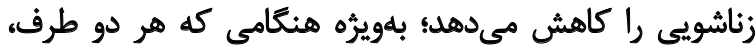

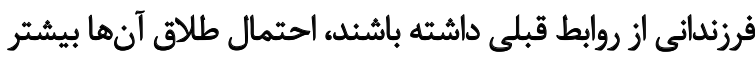

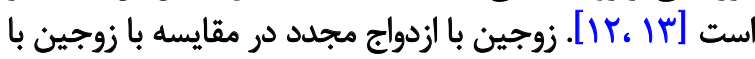

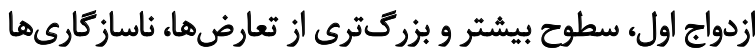

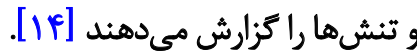
تجربيات در روابط كذشته باعث مى بـود افراد با دشوارىهاى

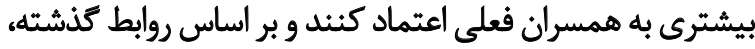

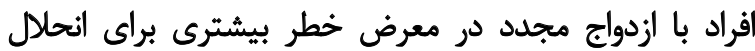

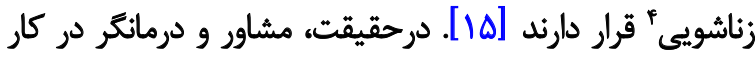

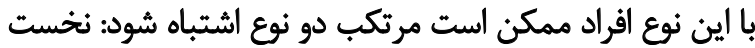

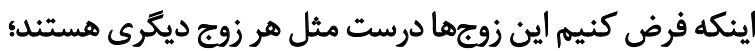

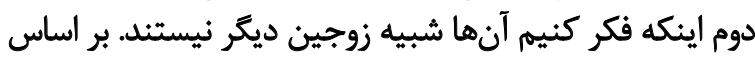

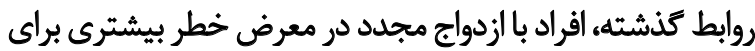

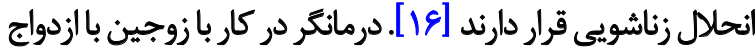

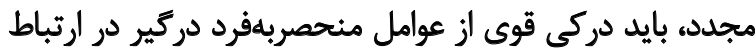

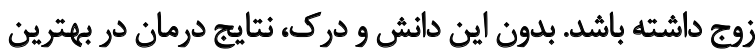

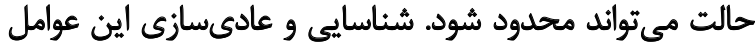

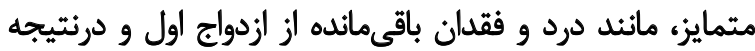

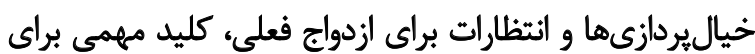

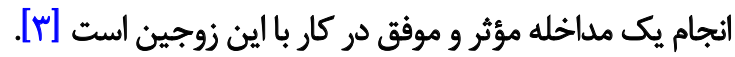
زوجدرمانى مبتنى بر بازسازى عاطفى ه از جمله درمانهايى

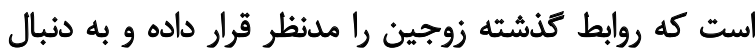

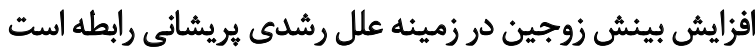

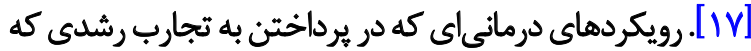

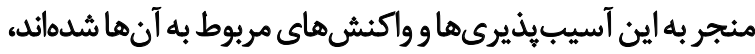

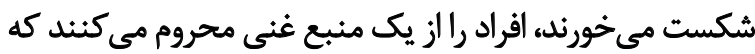

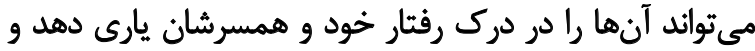

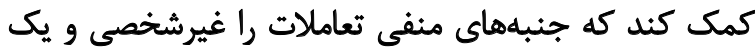

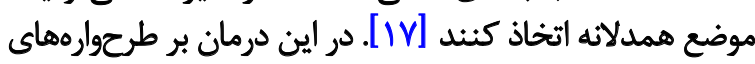

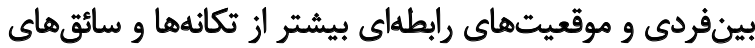

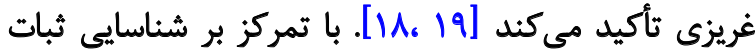

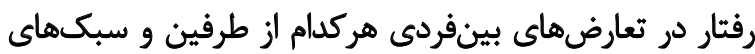

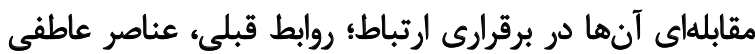

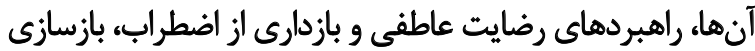

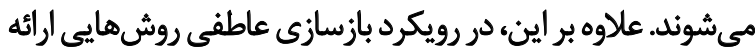

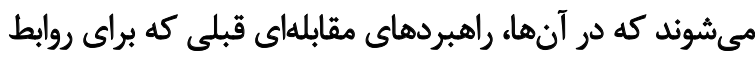

4. Marital dissolution

5. Affective - reconstructive couple therapy 
جدول ا. صورت جلسهماى زوجدرمانى مبتنّي بر بازسازى عاطفى

\begin{tabular}{|c|c|}
\hline مجتواي جلسات & جلسه \\
\hline درمان، جلى جلسات، بيان قوانين، ايجاد توافق مشترك، محدود كردن مبادلات منفى، ارائه يك جارجوب شفاف از مشكلات زوج و ترسيم اهداف & اول اول \\
\hline بررسى بحران هاى ناتوان كننده (در اين جلسه نحوه برخورد زوج با بحرانهاى ارتباطى ـ فعال و منفعلانه ـ بررسى مى شود). & دوم \\
\hline تقويت واحد زناشويى (در اين جلسه درمانكر به دنبال كاهش ثبادلات منفى زوجين و جايكزينى ثبادلات مثبت است). & سوم \\
\hline 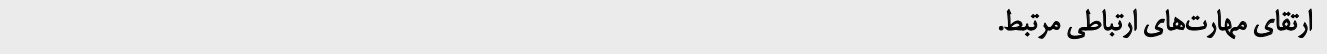 & جهارم \\
\hline بله جالش كشيلن مؤلفههاى شئختى يريشانى رابطه. & هئجم \\
\hline بررسى منابع رشدى يريشانى رابطه (در اين جلسه زوج درمانكر به اهميت روابط كذشته و تأثير تاريخحه هر فرد بر روابط زوج ميبردازد). & تششم \\
\hline 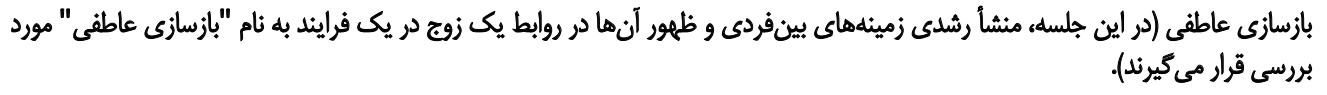 & 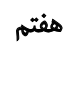 \\
\hline جمعبندى نهاييء اجراي ابزارها، تقدير و تشكر و إيان جلسات. & هشتمبم \\
\hline
\end{tabular}

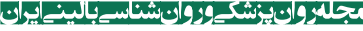

نام خانوادكى تكميل شدند ثامحرمانه بودن اطلاعات تأمين شود.

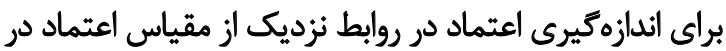

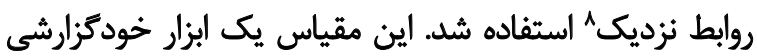

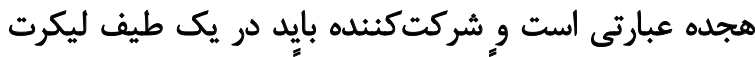

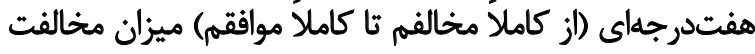

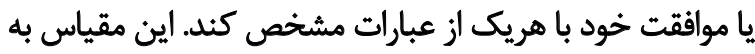

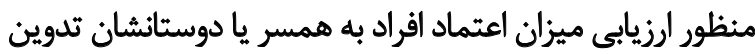

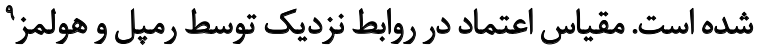

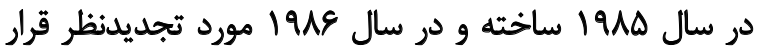

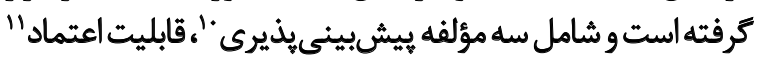

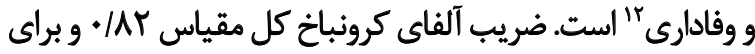

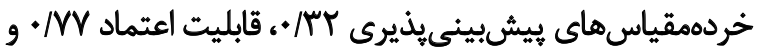

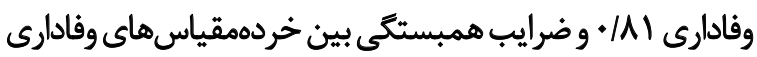

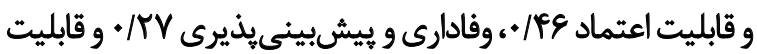

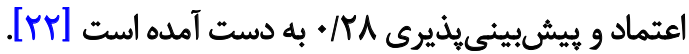

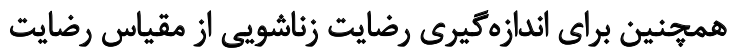

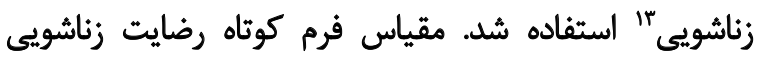

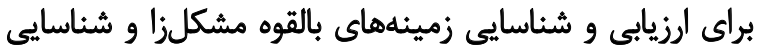

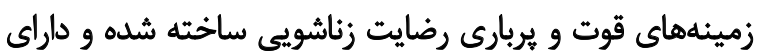

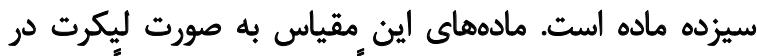

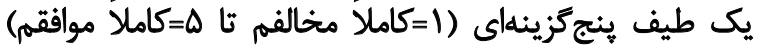

8. Trust in Close Relationships (TCRS)

9. Rempel \& Holmes

10. Predictability

11. Dependability

12. Faith

13. Marital Satisfaction Scale (MSS)
آمد. در مرحله بعد از ميان زوجهاي واجد شرايط، سه زوج

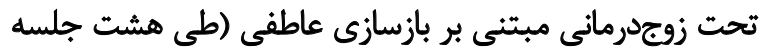

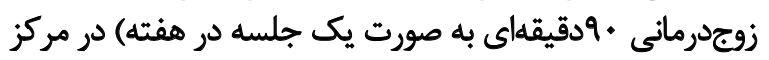

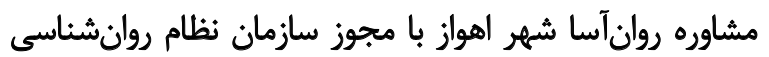

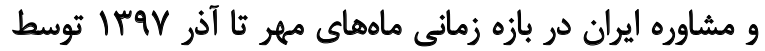

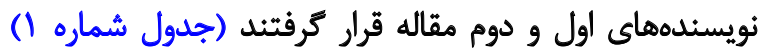

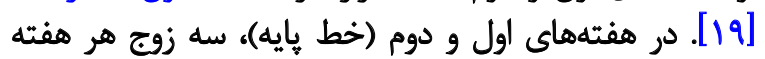

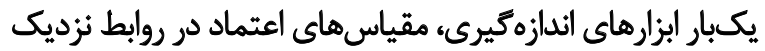

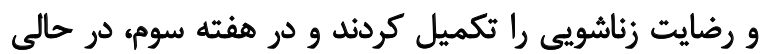

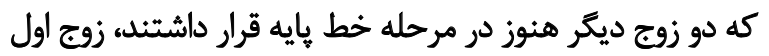

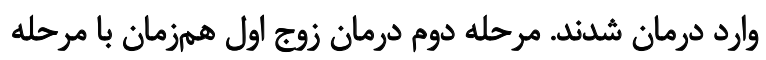

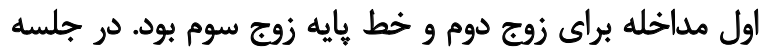

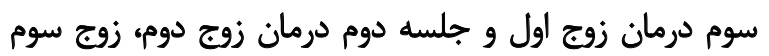

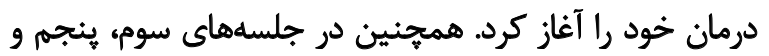

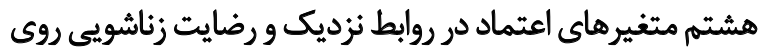

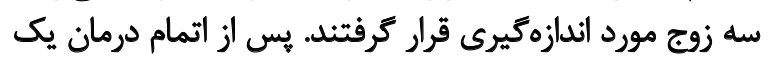

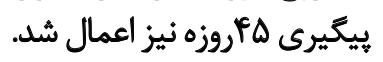

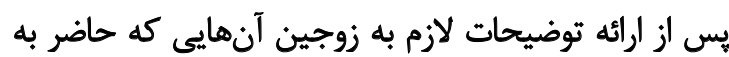

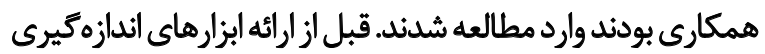

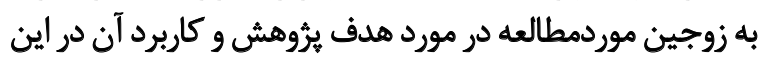

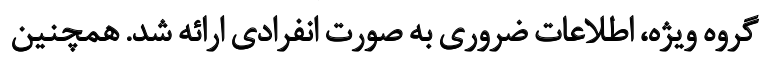

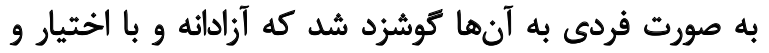

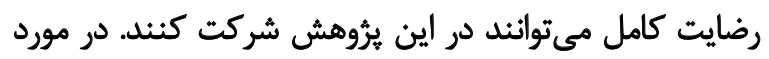

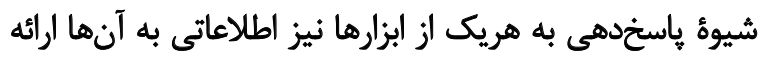

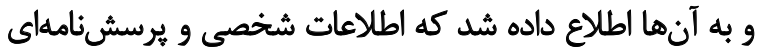

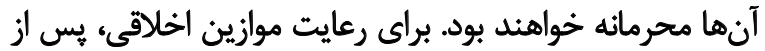

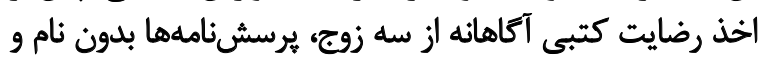


كه براى زوجهاى اول، دوم و سوم نسبت به مراحل خط زيايه و

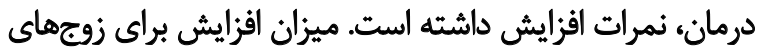

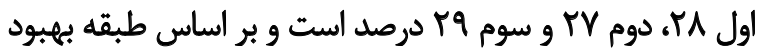

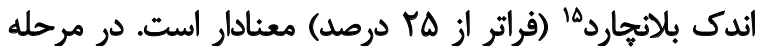

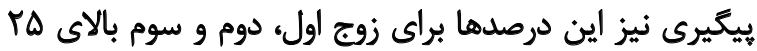

$$
\text { درصد و معنادار هستئد. }
$$

شاخص تغيير پايا به ترتيب در پايان درمان و وإيان مرحله

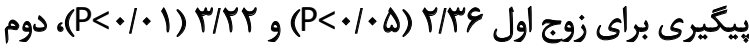

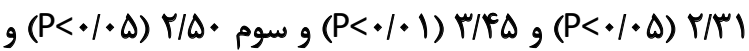

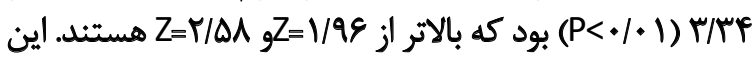

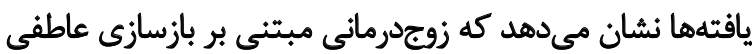

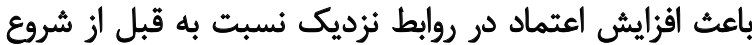

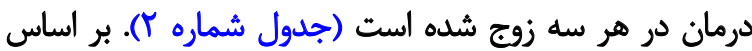

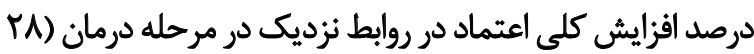

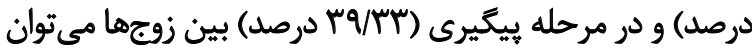

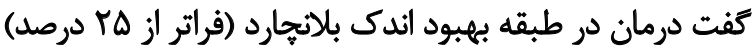

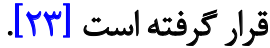

15. Blanchard

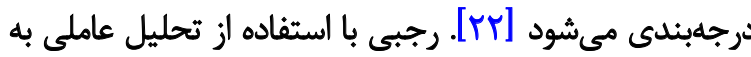

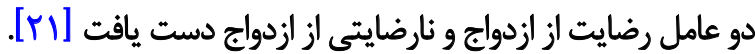

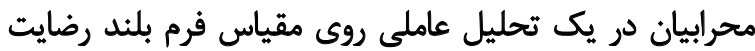

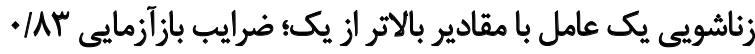

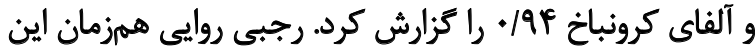

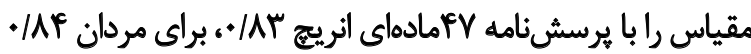

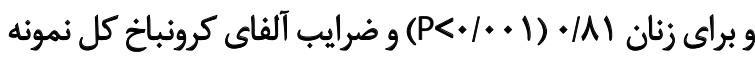

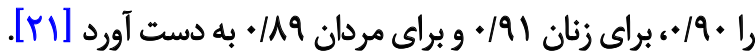
تجزيه و تحليل دادهها با استفاده از روشهاى تحليل ديداري

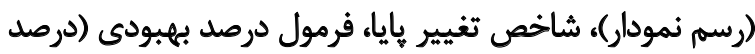
افزايش) و مقايسه هنجارى انجام شد.

Latêt

جدول شماره ب نشان مىدهد كه ميانكين ميزان اعتماد در

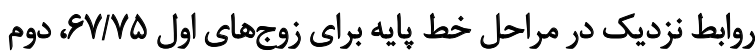

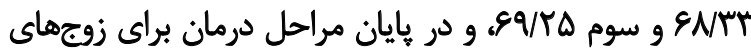

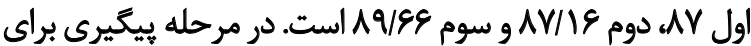

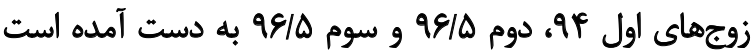

14. Visual analysis

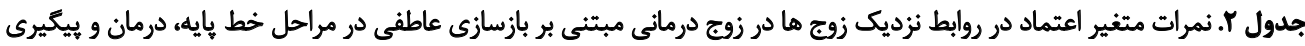

\begin{tabular}{|c|c|c|c|c|}
\hline \multicolumn{4}{|c|}{ زوجدرمانى مبتنى بر بازسازى عاطفى } & \\
\hline زوج سوم & زوج دوم & زوج اول & زوج مراحل درمان & \\
\hline ENA & $8 / \Delta$ & $8 A$ & حطظ بايه 1 & \multirow{5}{*}{ خط بايه } \\
\hline ex/o & END & eV/O & حطا بايه r & \\
\hline$V / \Delta$ & v. & & حطظ بايه r & \\
\hline$V / \Delta$ & & & خط يايه P & \\
\hline eq/ra & ENTH & EVIVD & ميانكين مرحله خط بايه & \\
\hline Ar & A) & ra & جلسه سوم & \multirow{7}{*}{ 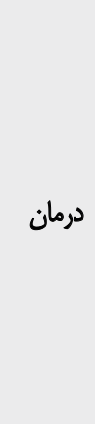 } \\
\hline 19/ब & $N / \Delta$ & Ne & جلسه ينجم & \\
\hline १V/ब & qf & $q$ & جلسه هشتم & \\
\hline 19/8 & $A V / \backslash \&$ & AV & ميانكين مرحله درمان & \\
\hline$r / \Delta$. & $M / M$ & $r / R$ & شاخص تغيير هايا (درمان) & \\
\hline \multirow[t]{2}{*}{ rq } & rr & ra & درصد افزايش اعتماد بعد از درمان & \\
\hline & rA & & درصد افزايش كلى بعد از درمان & \\
\hline$v / 0$ & $q 8 / \Delta$ & qf & ييكيرى & \multirow{4}{*}{ ييكيرى } \\
\hline$m / m e$ & T/Fo & $M / T$ & شاخص تغيير بايايا (ييكيرى) & \\
\hline \multirow[t]{2}{*}{ mq } & fi & ra & درصد افزيش اعتماد يس از ييكيرى & \\
\hline & 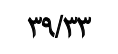 & & درصد افزايش كلى يس از ييكيرى & \\
\hline
\end{tabular}



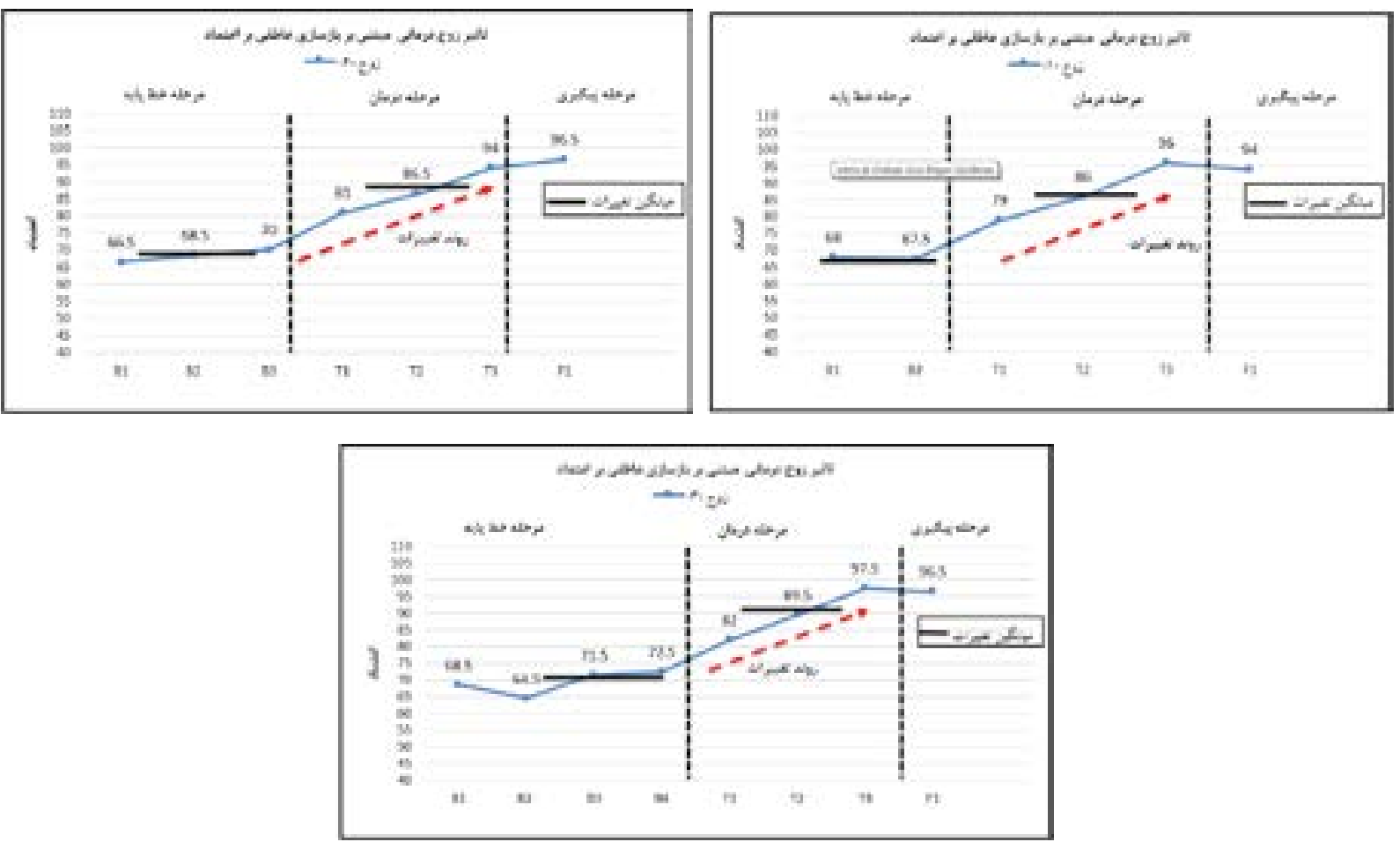

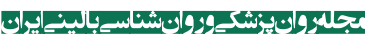

تصوير ا. روند تغيير نمرههاى متغير اعتماد در روابط نزديك در مراحل خط هايه، درمان و ييكيرى

جدول بادرجه آزادى الهاست. بنابراين دو كروه در متغير اعتماد

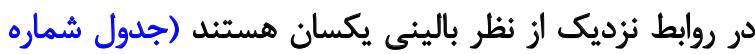

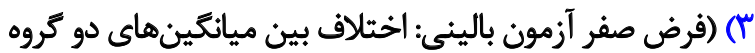

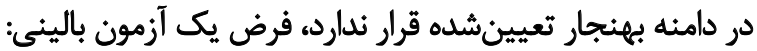

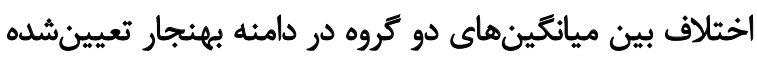

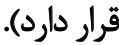
أز آزمون آمارى .$r$

$$
\begin{gathered}
\operatorname{trad}^{t(d f)=\left(\frac{M_{N}-M_{c}}{S E_{N}-c}\right)} \\
t_{(51)}=\left(\frac{93 / 27-87 / 94}{7 / 72}\right)=0 / 69 \\
t_{(51)}=0 / 69<t
\end{gathered}
$$

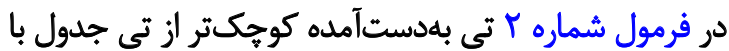

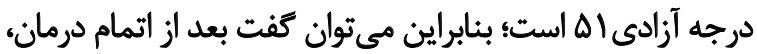

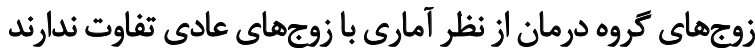

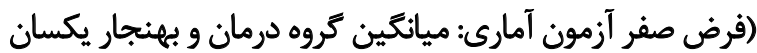

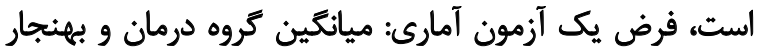

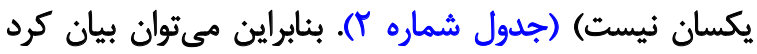

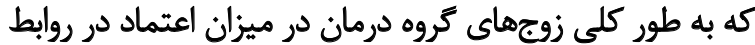
تزديك از نظر بالينى بازوجهاي كروه بروه بهنجار تفاوت ندان ندارد (تصوير

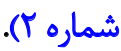

همانكونه كه در تصوير شماره ا مشاهده ميشود، ميانكين

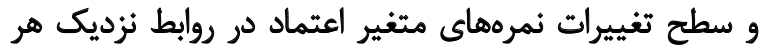

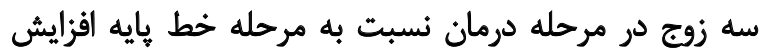

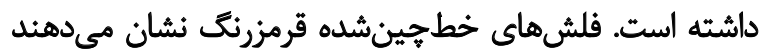

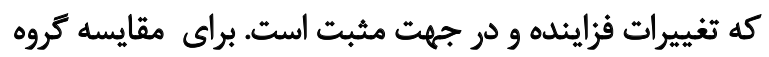

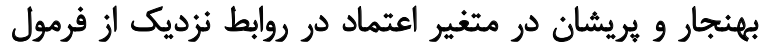

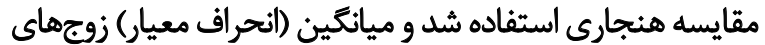

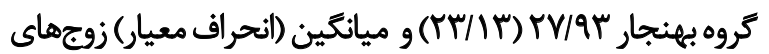

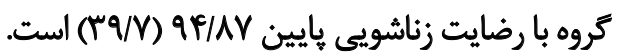

\section{تعيين طيف تُرْديكى}

طيف نزديكى از يك انحراف استاندارد كمتر از ميانكين كروه

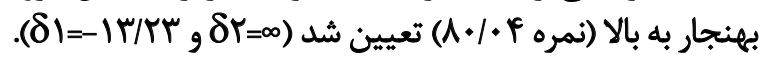

$$
\text { آزمون يكساني باليني }
$$

$$
\begin{gathered}
S E_{N-C}=\left\{\left[\frac{(50-1) 13 / 23^{2}+(3-1) 7 / 39^{2}}{50+3-2}\right]\left[\frac{1}{50}+\frac{1}{3}\right]\right\}^{1 / 2}=7 / 72 \\
t_{(51)}=\left(\frac{93 / 27-87 / 94-(-13 / 23)}{7 / 72}\right)=2 / 41 \\
t_{(51)}=2 / 41>t
\end{gathered}
$$

فرمول شماره ا نشان مى دهد تى بهدستآمده بزركتر از تى 


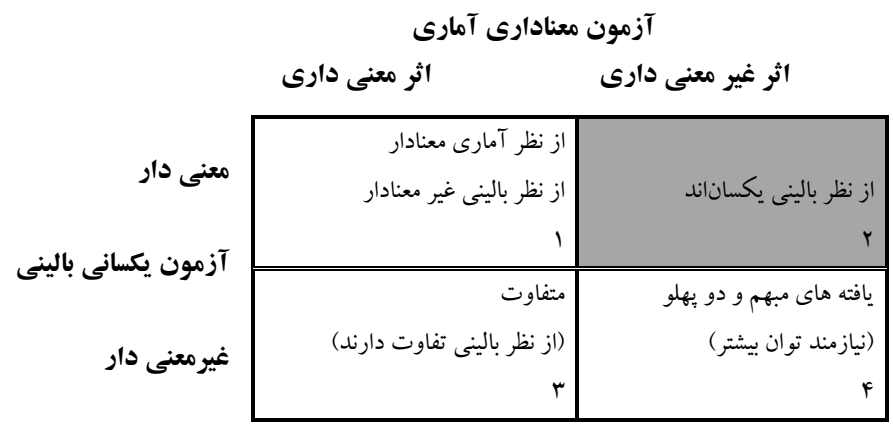

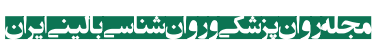

جدول r. طبقهبندى نتايج آزمونهاى معثادارى آمارى تأثيرات با استفاده از آزمونهاى يكسانى آمارى و بالينى در متغير اعتماد در روابط نزديك

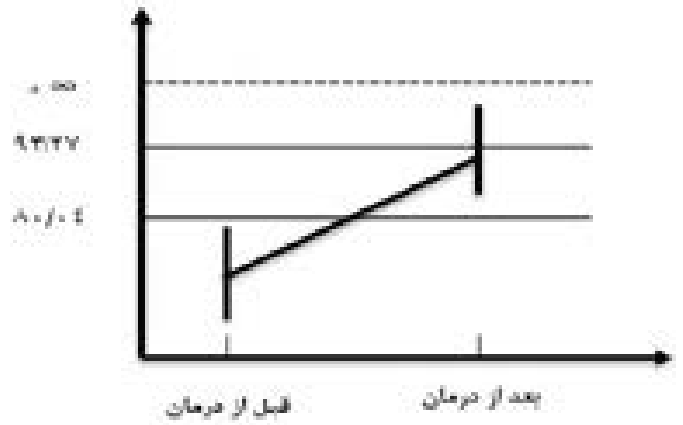

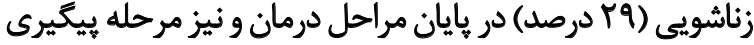

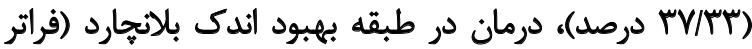

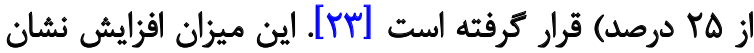

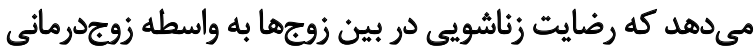
مبتنى بر بازسازى عاطفى افزايش يافته است. تصوير شماره ب نشان مى دهد كه ميانتين و سطح تغييرات

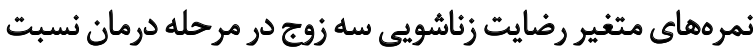

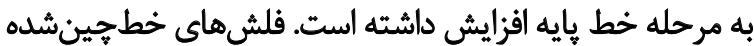

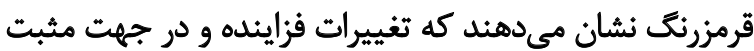

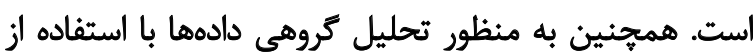

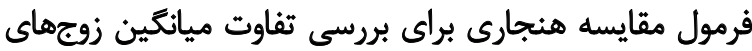

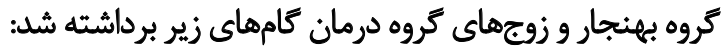
در متغير رضايت زناشويى براى محاسبه مقايسه هنجارى،

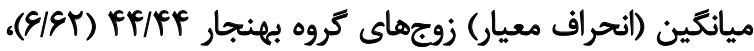

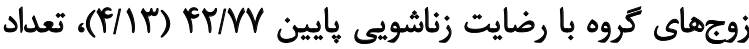

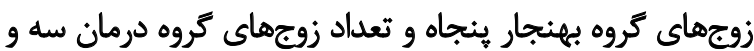

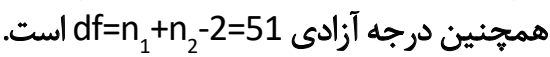

\section{تعبيين طيف نزوديكى}

طيف نزديكى از يك انحراف استاندارد كمتر از ميانكين گروه
همانطور كه در تصوير شماره Y مشاهده مى مُشود، ميانتين

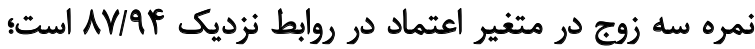

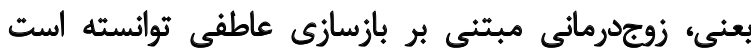

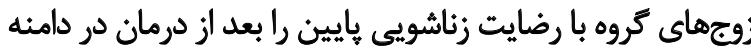

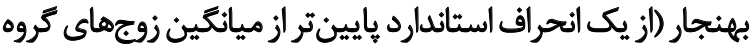

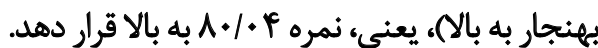

همانطور كه جدول شماره f نشان مى مدهد، ميانگين نمرات

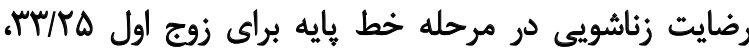

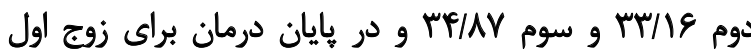
زF/AT

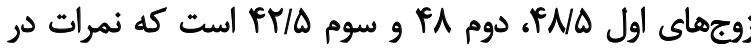

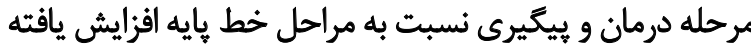

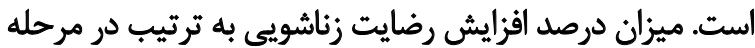

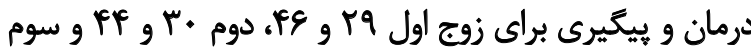

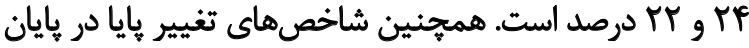

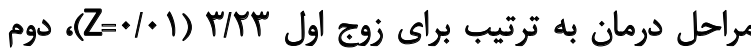

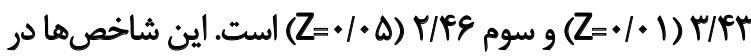

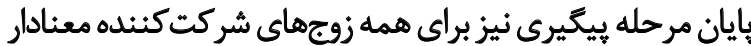

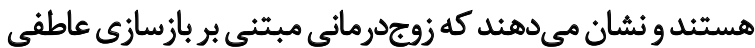

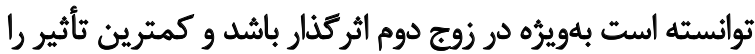

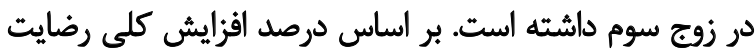


جدول P. نمرات متغير رضايت زناشويى زوج ها در زوج درمانى مبتنى بر بازسازى عاطفى در مراحل خط هايه، درمان و بيكيرى

\begin{tabular}{|c|c|c|c|c|}
\hline \multicolumn{4}{|c|}{ زوجدرمانى مبتىى بر بازسازى عاطفى } & \multirow{2}{*}{ 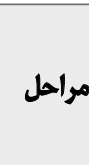 } \\
\hline زوج سوم & 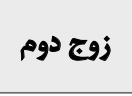 & زوج اول & مراحل درمان & \\
\hline$\Gamma \Delta / \Delta$ & $\pi / \Delta$ & rr & خط يايه 1 & \multirow{5}{*}{ خط يايه } \\
\hline ra & $\pi / \Delta$ & $\pi / \Delta$ & خط بايه r & \\
\hline$\pi / \Delta$ & $r / \Delta$ & & خط بايه ب & \\
\hline$r \Delta / \Delta$ & & & خط بايه ب & \\
\hline$\Gamma \varphi / A \gamma$ & Tr/le & $\pi / r \Delta$ & ميانكين مرحله خط يايه & \\
\hline pq & pq & $r V / \Delta$ & جلسه سوم & \multirow{7}{*}{ درمان } \\
\hline$F V / \Delta$ & $\mathrm{Fr} / \mathrm{\Delta}$ & r & جلسه ينجم & \\
\hline re & FND & pA & 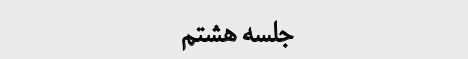 & \\
\hline$r T / / S$ & 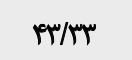 & $\mu r / A \mu$ & ميانكين مرحله درمان & \\
\hline$r / \& Q$ & $r / F r$ & $r / r$ & شاخص تغيير يايا (درمان) & \\
\hline \multirow[t]{2}{*}{$\mu^{p}$} & r. & ra & درصد افزايش رضايت زناشويى بعد از درمان & \\
\hline & ra & & درصد افزايش كلى بعد از درمان & \\
\hline$\mu r / \Delta$ & PA & PND & بيكيرى & \multirow{4}{*}{ بيكيرى } \\
\hline$r / \Delta A$ & $\Delta / \cdot 1$ & $e / M$ & شاخص تغيير هايا (ييكيرى) & \\
\hline \multirow[t]{2}{*}{ rr } & pr & is & درصد افزايش رضايت زناشويى يس از بيكيرى & \\
\hline & $r V / T r$ & & درصد افزايش كلى يس ازي ييكيرى & \\
\hline
\end{tabular}

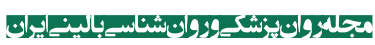

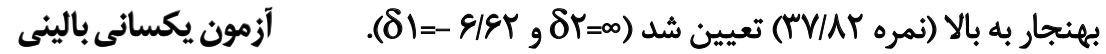
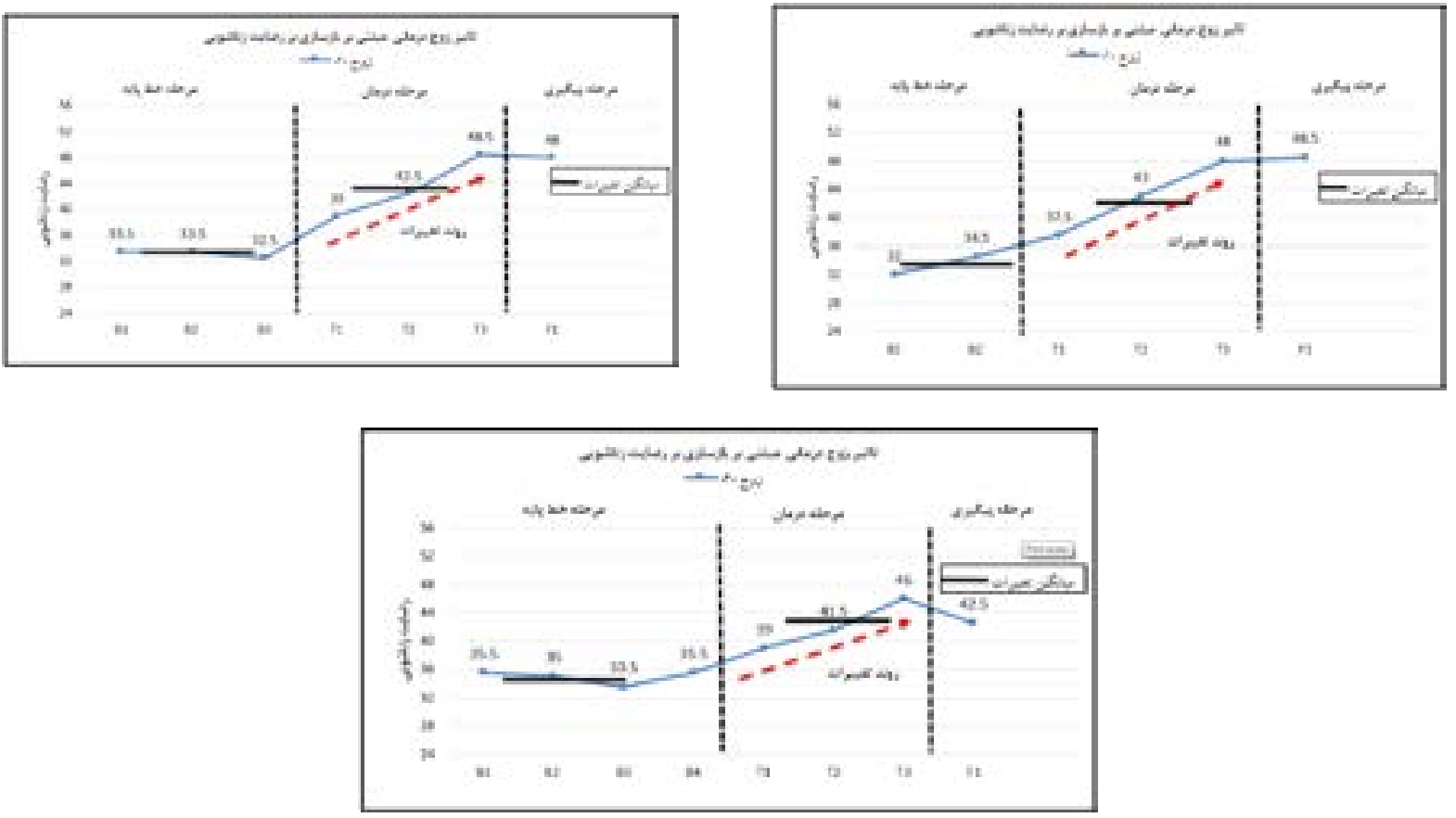

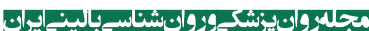

تصوير "ا. روند تغيير نمرههاى متغير رضايت زناشويى در مراحل خط بايه، درمان و بيكيرى 
بنابراين مي توان كفت زوجهاي درمان با زوجهاى كروه بهنجار

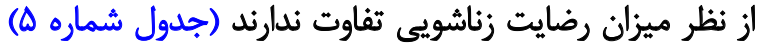

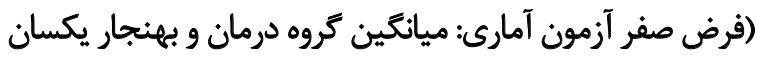

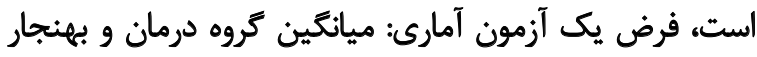

$$
\text { يكسان نيست) (جدول شماره F). }
$$

در تفسير اين يافته ميتوان بيان كرد كه زوجهاى تحت درمان

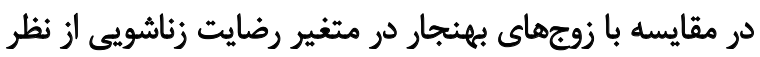
بالينى و آمارى تفاوتى ندارد.

همانطور كه در تصوير شماره f مشاهده مي مشود، ميانكين

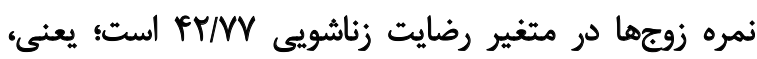

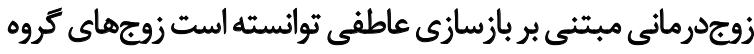

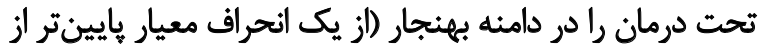

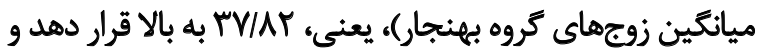
باعث افزايش رضايت زناشويى در زوجها شده است.

بحث

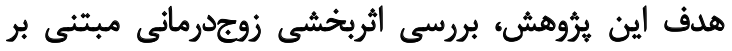

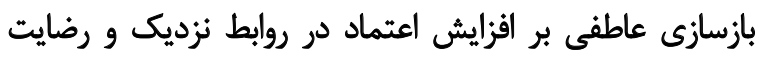

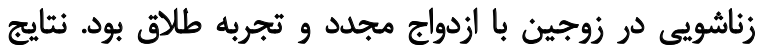

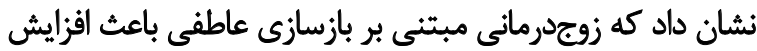

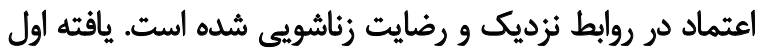
اين يُروهش نشان داد كه اين روش درمانى باعث افزايش اعتماد درد

$$
\begin{gathered}
S E_{N-C}=\left\{\left[\frac{(50-1) 6 / 62^{2}+(3-1) 4 / 13^{2}}{50+3-2}\right]\left[\frac{1}{50}+\frac{1}{3}\right]\right\}^{1 / 2}=3 / 86 \\
t_{(51)}=\left(\frac{44 / 44-42 / 77-(-6 / 62)}{3 / 86}\right)=2 / 14 \\
t_{(51)}=2 / 14>t
\end{gathered}
$$

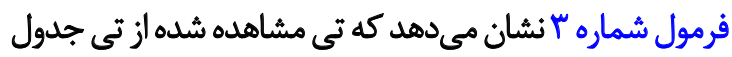

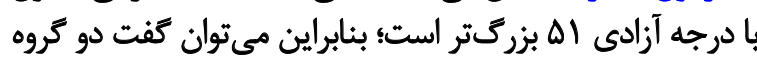

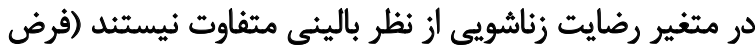

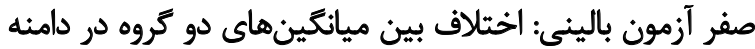

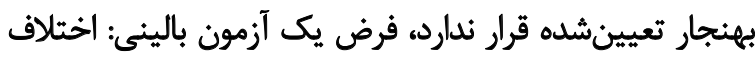
بين ميانكينهاى دو تروه در دامنه بهنجار تعيينش فرده قرار برار دارد).

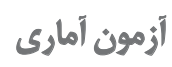

$$
. f
$$

$$
\begin{gathered}
\operatorname{trad}^{t(d f)=\left(\frac{M_{N}-M_{c}}{S E_{N-C}}\right)} \\
t_{(51)}=\left(\frac{44 / 44-42 / 77}{3 / 86}\right)=0 / 43 \\
t_{(51)}=0 / 43<t
\end{gathered}
$$

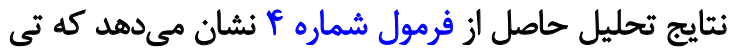

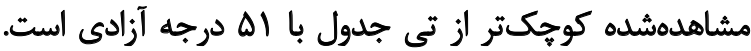

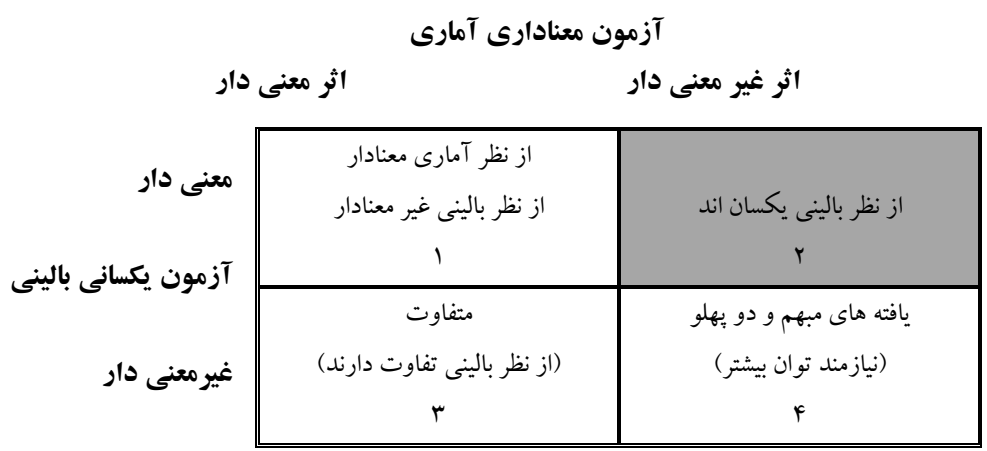

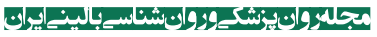

جدول ه. طبقهبندى نتايج آزمونهاى معنادارى آمارى تأثيرات با استفاده از آزمونهاى يكسانى آمارى و بالينى در متغير رضايت زناشويى

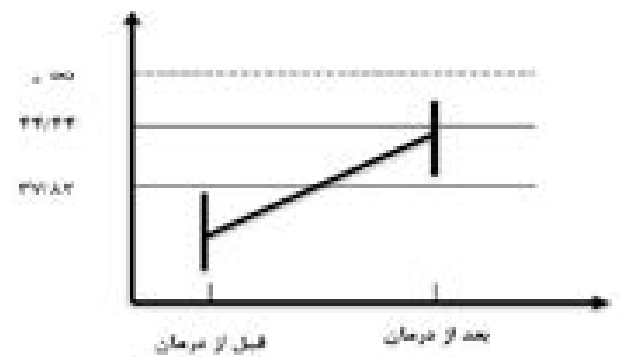

تصوير F. نتايج ميانكين آزمون هاى معنادارى آمارى قبل و بعد از درمان در متغير رضايت زناشويى 
عناصر شناختى و بررسى علل رشدى يريشانى رابطه است [IV]

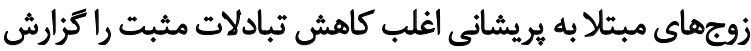

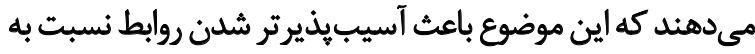

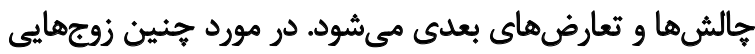

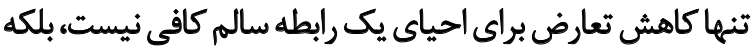

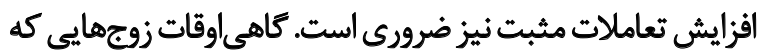

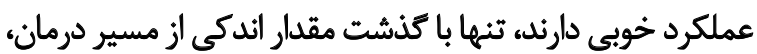

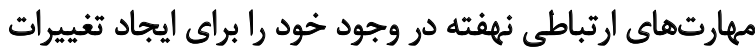
مثبت مورد توافق به كار مي كيرند [1/1]].

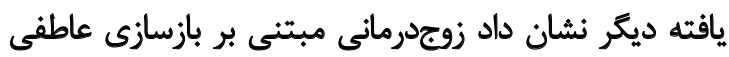

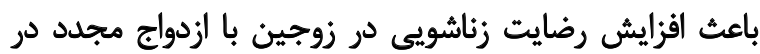

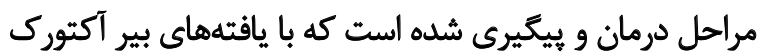

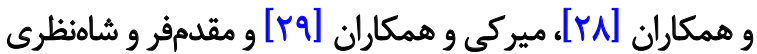

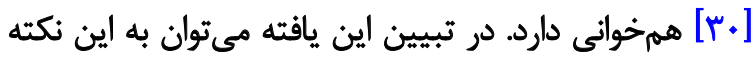

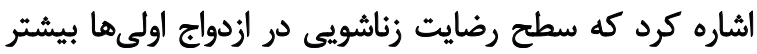

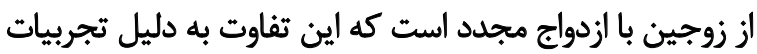

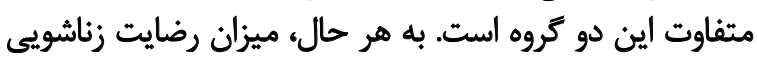

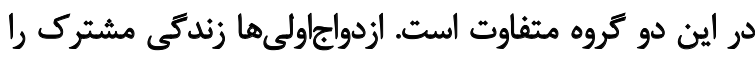

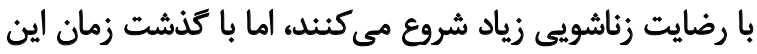

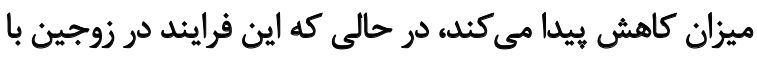

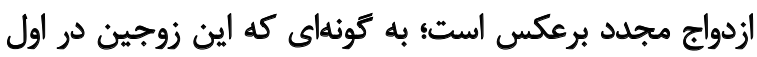

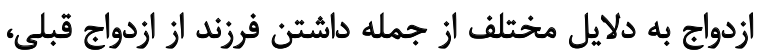

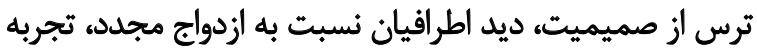

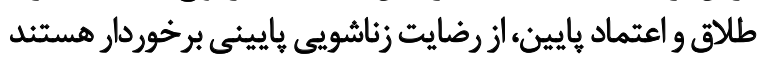

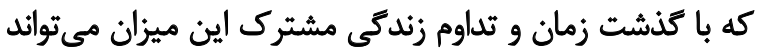

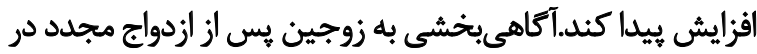

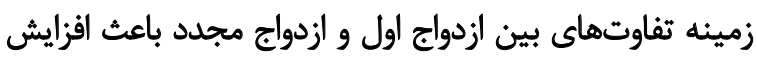

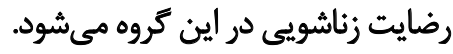

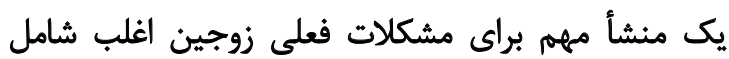

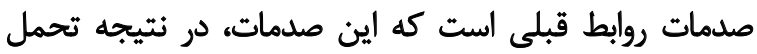

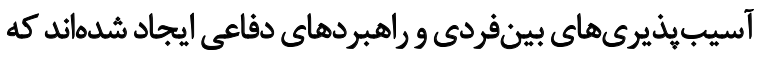

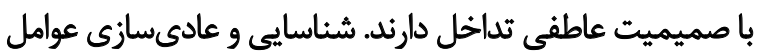

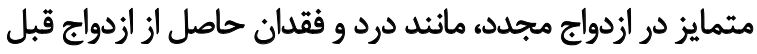

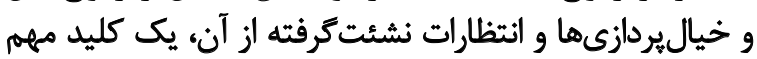

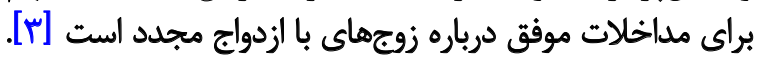

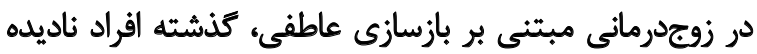

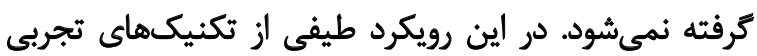

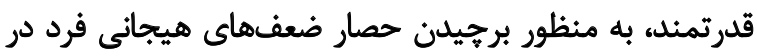

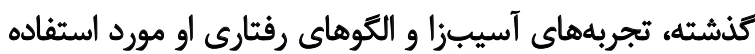

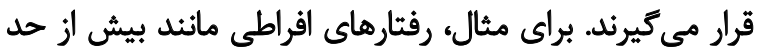

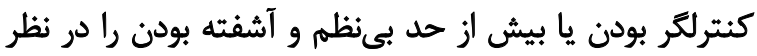

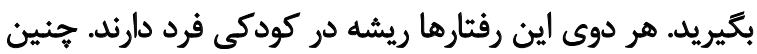

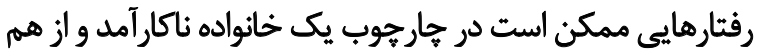

روابط تزديك در زوجهاى با ازدواج مجدد شده است كه با يافتههاى

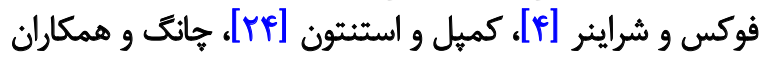

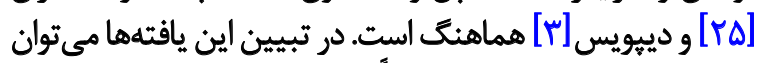

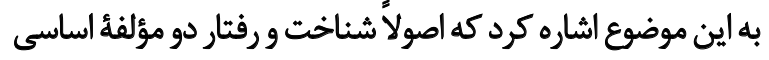

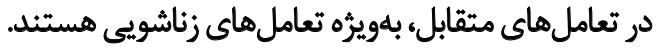

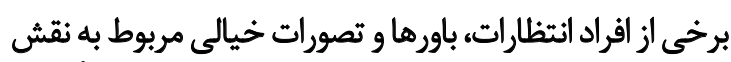

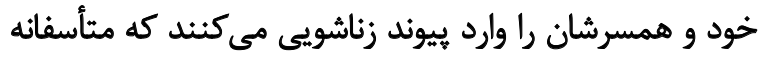
بسيارى از اين انتظارات بسيار غيرمنطقى هستيند واز ازين اين رو سبب

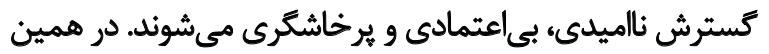

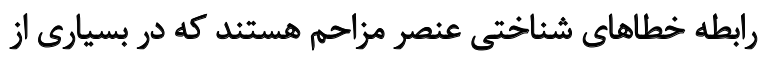

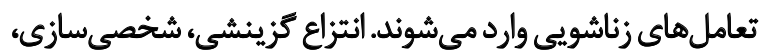

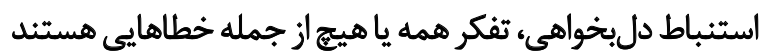

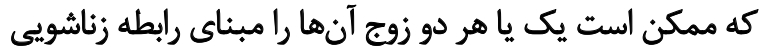

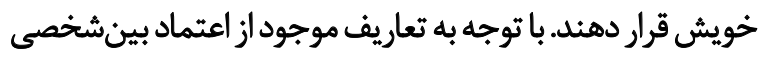

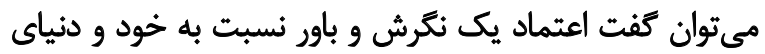

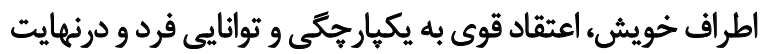

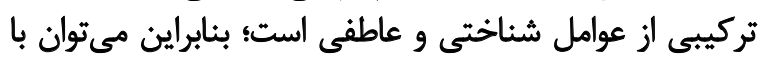

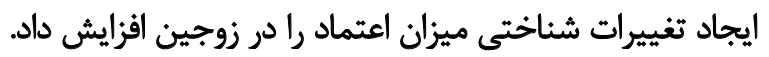

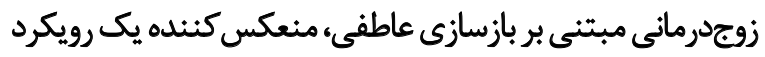

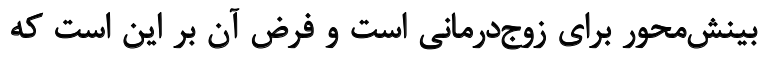

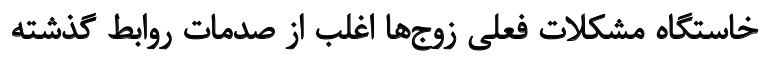

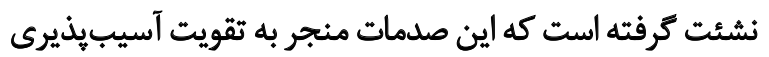

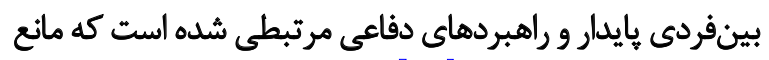

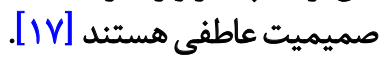

وقتى فرد در مورد خاستغاه الكوهاى ناكار آمد خودآكاهى يبيدا

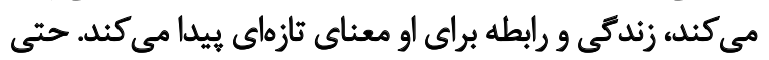

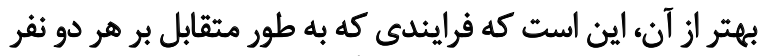

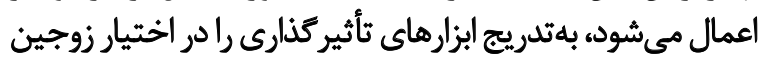

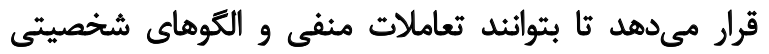

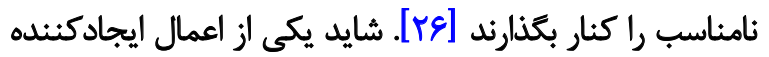

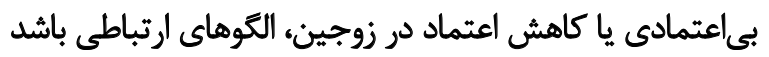

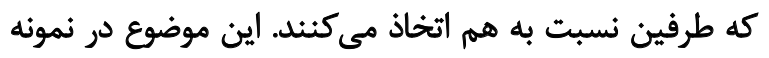

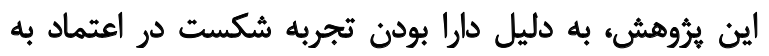

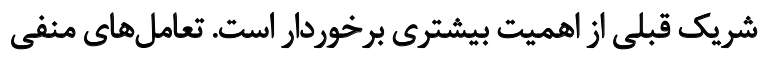

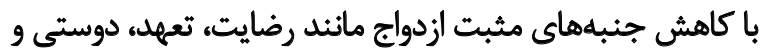

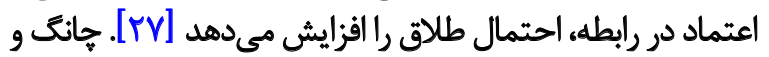

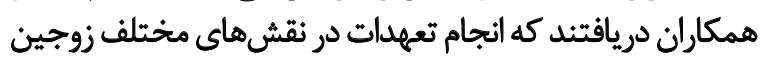

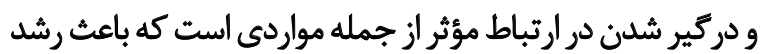

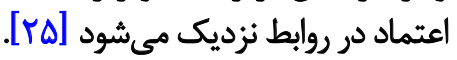

در زوجدرمانى مبتنى بر بازسازى عاطفى يس از ايجاد توافق

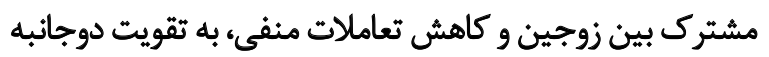

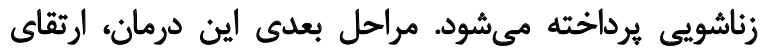

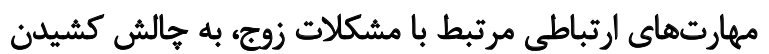




$$
\text { جمران اهواز است. }
$$

مشار كت ثويسند منان

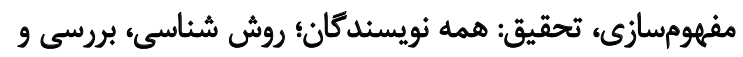

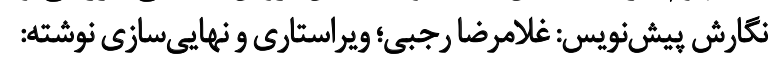

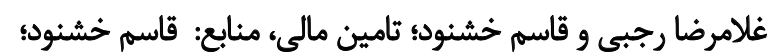
نظارت: غلامرضار رجبى، منصور سوداني، رضا خجرسته مهر.

$$
\text { ت تعارض مئاقع }
$$

بنابر اظهار نويسنده مسئول، اين مقاله تعارض منافع نداشته است.

$$
\text { تشكر و قدردانى }
$$

بدينوسيله از همه شركت كنتدكان، مسئولان محترم مراكز

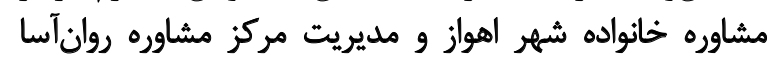

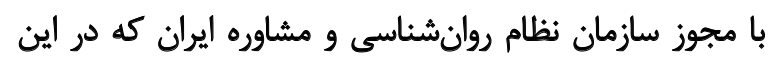
يروهش ما را يارى كردند تشكر مي كنيم.

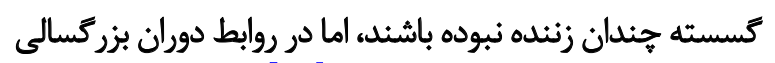

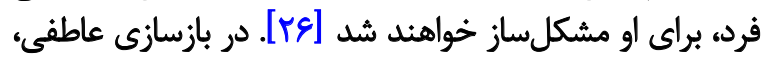

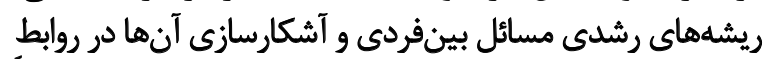

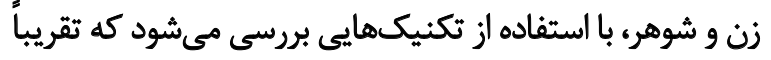

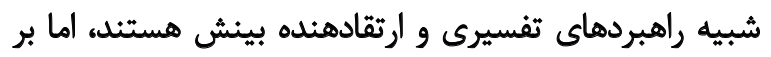

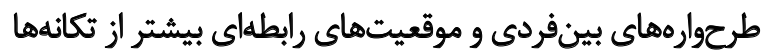
و سائق هاى غريزى تأكيد مي كنيند [IV]

در اين درمان با تمركز بر شناسايى ثبات رفتار در تعارضات

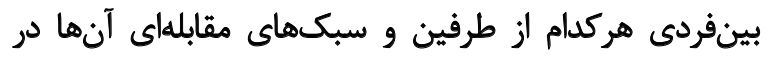

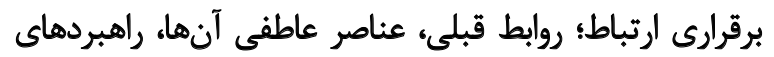

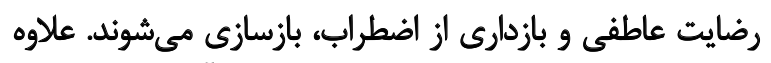

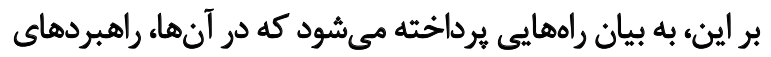

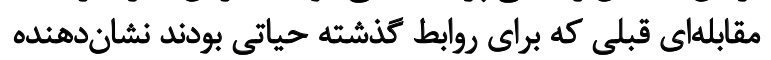

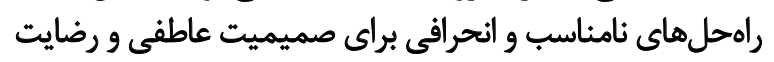

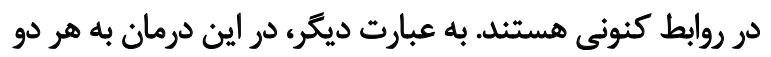

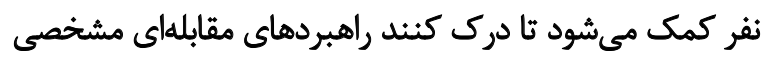

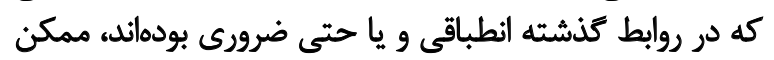

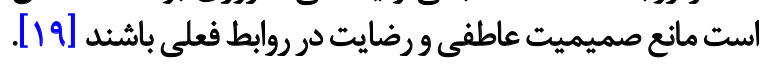

\section{نتيجنكيرى}

زوجدرمانى مبتنى بر بازسازى عاطفى با آكاهى بخشى و افزايش

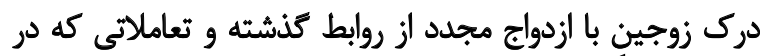

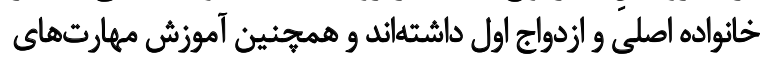

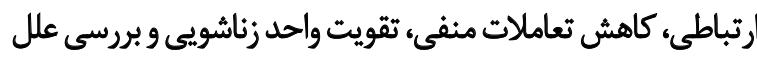

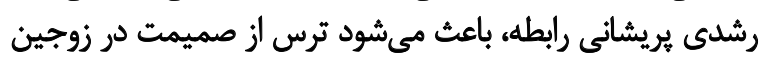

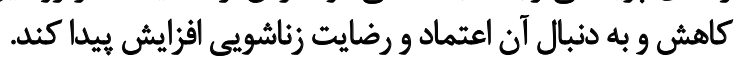

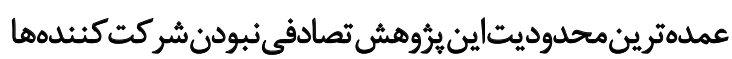

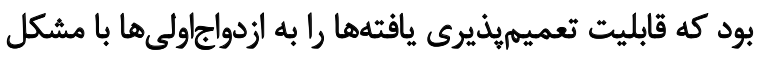

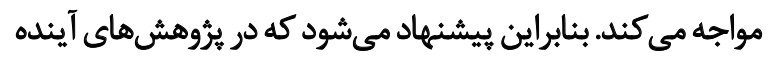

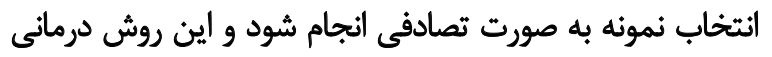

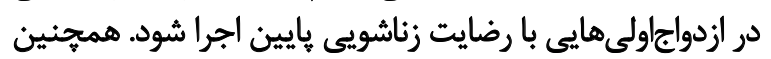

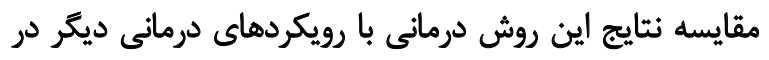
زوجين با ازدواج مجدد مي تواند مفيد باشد بائد

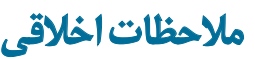

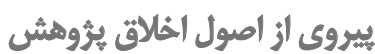

اين مقاله با كد اخلاق و 9 . . مصوب كميثه اخلاق دانشكاه

$$
\text { شهيد جمران اهواز است. }
$$

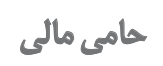

اين مقاله بركرفته از ياياننامه دكترى نويسنده دوم در كروه

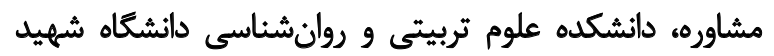




\section{References}

[1] Maleki H. [Training and counseling on remarriage (Persian)]. Tehran: Avaye Noor; 2016. http:/ /opac.nlai.ir/opacprod/bibliographic/4187994

[2] Pasley K, Garneau C. Remarriage and stepfamily life. In: Walsh F, editor. Normal Family Processes: Growing Diversity and Complexity. New York: Guilford Press; 2012. p. 149-172. https://books.google.com/ books?id=3C15kY3XnMUC\&printsec

[3] Dupuis SB. Examining remarriage: A look at issues affecting remarried couples and the implications towards therapeutic techniques. Journal of Divorce \& Remarriage. 2007; 48(1-2):91-104. [DOI:10.1300/J087v48n01_05]

[4] Fox WE, Shriner M. Remarried couples in premarital education: Does the content match participant needs? Journal of Divorce \& Remarriage. 2014; 55(4):276-99. [DOI:10.1080/ 10502556.2014.901841]

[5] Faber AJ. Examining remarried couples through a Bowenian family systems lens. Journal of Divorce \& Remarriage. 2004; 40(3-4):121-33. [DOI:10.1300/J087v40n03_08]

[6] Iran's National Oraganization for Civil Registration. [Marriage and divorce data (Persian)] [Internet]. 2017 [Updated 2017]. Available from: http:/ / www.sabteahval.ir/.https:/ / www.sabteahval.ir/avej/Page.aspx?mId=49826\&ID=3257 $\&$ Page=Magazines/SquareshowMagazine

[7] Adler-Baeder F, Higginbotham B. Implications of remarriage and stepfamily formation for marriage education. Family Relations. 2004; 53(5):448-58. [DOI:10.1111/j.01976664.2004.00053.x]

[8] Stokes SB, Wampler RS. Remarried clients seeking marital therapy as compared to those seeking family therapy: Differences in levels of psychological and marital distress. Journal of Divorce \& Remarriage. 2002; 38(1-2):91-107. [DOI:10.1300/J087v38n01_05]

[9] Deal RL, Olson DH. The smart stepfamily marriage: Keys to success in the blended family. Grand Rapids: Baker Publishing Group; 2015. https://books.google.com/ books?id=s5gQBgAAQBAJ\&dq

[10] Pasley K, Koch MG, Ihinger-Tallman M. Problems in remarriage: An exploratory study of intact and terminated relationships. Journal of Divorce \& Remarriage. 1994; 20(12):63-83. [DOI:10.1300/J087v20n01_04]

[11] Martin-Uzzi M, Duval-Tsioles D. The experience of remarried couples in blended families. Journal of Divorce \& Remarriage. 2013; 54(1):43-57. [DOI:10.1080/10502556.2012 .743828]

[12] DeGreeff BL, Platt CA. Green-eyed (step) monsters: Parental figures' perceptions of jealousy in the stepfamily. Journal of Divorce \& Remarriage. 2016; 57(2):112-32. [DOI :10.1080/10502556.2015.1127876]

[13] Amato PR. Research on divorce: Continuing trends and new developments. Journal of Marriage and Family. 2010; 72(3):650-66. [DOI:10.1111/j.1741-3737.2010.00723.x]

[14] Gold JM. Understanding the experiences of husbands in step-couples: Implications for strengthening step- family marriages. The Family Journal. 2016; 24(4):415-9. [DOI:10.1177/1066480716663496]

[15] Sweeney MM. Remarriage and stepfamilies: Strategic sites for family scholarship in the 21st century. Journal of Marriage and Family. 2010; 72(3):667-84. [DOI:10.1111/ j.1741-3737.2010.00724.x]

[16] Wheeler G, Backman S, editors. On intimate ground: A gestalt approach to working with couples. San Francisco; Jossey-Bass Publishers; 1994. https://books.google.com/ books?id=hrvuyUzed3oC\&dq

[17] Gasbarrini MF, Snyder DK. Affective reconstructive approach to couple therapy. In: Lebow J, Chambers A, Breunlin D, editors. Encyclopedia of Couple and Family Therapy. Cham: Springer; 2017. pp. 1-6. [DOI:10.1007/978-3-31915877-8_928-1]

[18] Snyder DK. Affective reconstruction in the context of a pluralistic approach to couple therapy. Clinical Psychology: Science and Practice. 1999; 6(4):348-65. [DOI:10.1093/ clipsy.6.4.348]

[19] Snyder DK, Mitchell AE. Affective-reconstructive couple therapy: A pluralistic, developmental approach. In: Gurman AS, editor. Clinical Handbook of Couple Therapy. New York: The Guilford Press; 2008. https:/ / psycnet.apa. org/record/2008-09621-012

[20] Rajabi GR, Naderi Nobandegani Z, Amanolahi A. [Effect of systemic- constructive couple therapy on mutuality in distressed couples (Persian)]. Family Counseling and Psychotherapy. 2015; 5(3):1-21. http://fcp.uok.ac.ir/article_42705_en.html

[21] Rajabi GR. [Factorial structure of marital satisfaction scale in married staff members of Shahid Chamran University (Persian)]. Iranian Journal of Psychiatry and Clinical Psychology. 2010; 15(4):351-8. http://ijpcp.iums.ac.ir/ article-1-889-en.html

[22] Javidmehr F, Honarparvaran N, Ghaderi Z. [Validation of the Persian version of the trust in interpersonal relationships scale (Persian)]. Quarterly Journal of Family and Research. 2014; 11(2):21-36. http:/ / qjfr.ir/article-1-83-en.html

[23] Hamidpour H. [The importance of methodology in cognitive behavioral research (Persian)]. Baztab-e Danesh 2008; 3(10):49-56.

[24] Campbell L, Stanton SCE. Adult attachment and trust in romantic relationships. Current Opinion in Psychology. 2019; 25:148-51. [DOI:10.1016/j.copsyc.2018.08.004] [PMID]

[25] Chang JHY, Yang H, Yeh KH, Hsu SC. Developing trust in close personal relationships: Ethnic Chinese's experiences. Journal of Trust Research. 2016; 6(2):167-93. [DOI:10.108 0/21515581.2016.1207543]

[26] Simeone-DiFrancesco C, Roediger E, Stevens BA. Schema therapy with couples: A practitioner's guide to healing relationships. Hoboken, NJ: John Wiley \& Sons; 2015. [DOI:10.1002/9781118972700]

[27] Fathi Aghdam Gh, Ahadi H, Jomehri F, Farrokhi NA [The comparison of the effectiveness of communication skills training on marital conflicts and the quality of life among female students (Persian)]. 2011; 3(9):101-19. https://www.sid.ir/fa/Journal/ViewPaper.aspx?id=216807 
[28] Bir-Akturk E, Fisiloglu H. Marital satisfaction in Turkish remarried families: Marital status, stepchildren, and contributing factors. Journal of Divorce \& Remarriage. 2009; 50(2):119-47. [DOI:10.1080/10502550802365755]

[29] Mirecki RM, Chou JL, Elliott M, Schneider CM. What factors influence marital satisfaction? Differences between first and second marriages. Journal of Divorce \& Remarriage. 2013; 54(1):78-93. [DOI:10.1080/10502556.2012.743831]

[30] Moghadam Far N, Shah Nazari M. [The role of social support and early maladaptive schemas in marital satisfaction of married women (Persian)]. Iranian Journal of Nursing Research. 2017; 12(5):53-60. [DOI:10.21859/ijnr-12058] 
This Page Intentionally Left Blank 